\title{
DA NACIONALIZAÇÃO À ESCOLA BILÍNGUE: REFLEXÕES SOBRE A EDUCAÇÃO LINGUÍSTICA EM BLUMENAU/SC
}

\author{
DE LA NACIONALIZACIÓN A LA ESCUELA BILÍNGÜE: \\ REFLEXIONES SOBRE LA EDUCACIÓN LINGÜÍSTICA EN BLUMENAU/SC
}

\author{
FROM NATIONALIZATION TO BILINGUAL SCHOOLS: \\ REFLECTIONS ON LINGUISTIC EDUCATION IN BLUMENAU/SC
}

\author{
Melissa PROBST ${ }^{1}$ \\ Caique Fernando da Silva FISTAROL ${ }^{2}$ \\ Sandra POTTMEIER ${ }^{3}$
}

RESUMO: Este trabalho assenta-se numa visão de língua como direito, identidade de um grupo de fala, de imigrantes advindos da Europa no século XVIII, bem como de seus descendentes. Apesar dos processos de unificação da língua alemã vinculados ao ideal de nacionalização, ocorridos, o primeiro em 1911 (por Orestes Guimarães), e o segundo durante o Estado Novo (1937-1945), a língua alemã e a cultura teuto-brasileira mantêm-se presentes ainda nos dias hodiernos. Partindo de uma revisão de literatura, vislumbra-se compreender as novas tentativas de "resgate" da língua alemã, bem como a manutenção étnico-cultural em Blumenau (SC) a partir da implementação de uma escola bilíngue (português-alemão). Considera-se, que apesar da implementação da escola bilíngue como uma política linguística inclusiva que busca valorizar a língua de um grupo minoritário (alemão), há desafios ainda a serem superados: formação docente inicial e continuada bilíngue e o reconhecimento do dialeto alemão em uso por essa comunidade de fala.

PALAVRAS-CHAVE: Língua. Formação docente. Educação básica.

RESUMEN: Este trabajo se asienta en una visión de lengua como derecho, identidad de un grupo de habla, de inmigrantes provenientes de Europa en el siglo XVIII, así como de sus descendientes. A pesar de los procesos de unificación de la lengua alemana vinculados al ideal de nacionalización, ocurridos, el primero en 1911 (por Orestes Guimarães), y el segundo durante el Estado Nuevo (1937-1945), la lengua alemana y la cultura teuto-brasileña, si se siguen presentes en los días de hoy. A partir de una revisión de la literatura, imagina a entender los nuevos intentos de "rescate" de la lengua alemana, así como el mantenimiento étnica y cultural en Blumenau (SC) de la aplicación de una escuela bilingüe (portugués-alemán). Se considera, que a pesar de la implementación de la escuela bilingüe como una política lingüística inclusiva que busca valorar la lengua de un grupo minoritario (alemán), hay

\footnotetext{
${ }^{1}$ Instituto Federal Catarinense - (IFC), Araquari - SC - Brasil. Docente. ORCID <https://orcid.org/0000-00022326-3597>. E-mail: mel.probst@gmail.com

2 Secretaria Municipal de Educação de Blumenau - (SEMED), Blumenau - SC - Brasil. ORCID <https://orcid.org/0000-0001-7650-7324>. E-mail: cfersf@gmail.com

${ }^{3}$ Universidade Federal de Santa Catarina - (UFSC), Florianópolis - SC - Brasil. Doutoranda do Programa de PósGraduação em Linguística. ORCID <https://orcid.org/0000-0001-7328-8656>. E-mail: pottmeyer@ gmail.com
} 
desafíos aún a ser superados: formación docente inicial y continuada bilingüe y el reconocimiento del dialecto alemán en uso por esa comunidad.

PALABRAS CLAVE: Idioma. Formación docente. Educación básica.

ABSTRACT: This work is based on the perspective of language as a right, identity of a speech group, immigrants from Europe in the eighteenth century, as well as their descendants. In spite of the processes of unification of the German language linked to the ideal of nationalization, the first in 1911 (by Orestes Guimarães), and the second during the Estado Novo (1937-1945), the German language and the Teuto-Brazilian culture are still present in modern times. Starting from a literature review, we aim at understanding the new attempts to "rescue" the German language, as well as the ethnic-cultural maintenance in Blumenau (SC) from the implementation of a bilingual (Portuguese-German) school. Despite the implementation of the bilingual school as an inclusive linguistic policy that seeks to value the language of a minority (German) group, there are still challenges to be overcome: initial and continuing bilingual teacher education and recognition of the German dialect in use by this community.

KEYWORDS: Language. Teacher education. Basic education.

\section{Introdução}

O Brasil é, atualmente, um país de diversidade cultural, por consequência das políticas de imigração instauradas desde os tempos coloniais. Por isso, o Brasil é também um país constituído por diversas línguas, o que o torna um país plurilíngue (OLIVEIRA, 2009) e/ou multilíngue (MAHER, 2013), ao contrário do que se pensava no passado em que se considerava que “o português [era] a língua do Brasil”, conforme afirma Oliveira (2009, p. 20).

Tal pensamento retoma os escritos do Antigo Testamento, pontualmente, em Gênesis, 11, ao discorrer sobre o período em que a Torre de Babel estava sendo construída. Esse marco histórico apresenta uma diversidade de línguas que eram faladas naquela época e, tal fato, poderia gerar e/ou resultar em grandes desencontros e confusões (MAHER, 2013). Contudo, é a partir da Revolução Francesa que nasce o conceito de Estado-Nação e, com ele, a ideia de unificação do povo em torno da língua, a partir da "criação, [...] invenção de símbolos que reafirmassem essa unidade/uniformidade: bandeira, hino, língua nacional” (MAHER, 2013, p. 119).

A concepção de unificação da língua, no caso do Brasil, tem seu início na colonização com a proibição da língua geral a partir das reformas empreendidas pelo Marquês de Pombal, com vistas à extinção da língua falada entre índios e jesuítas. Mais adiante com a abolição da escravatura, em 1888 e, com a necessidade de obter mão de obra para os trabalhos agrícolas, 
muitos imigrantes chegaram ao Brasil, dentre eles, italianos e alemães (OLIVEIRA, 2009; MAHER, 2013), que, de sua terra natal trouxeram parcos recursos materiais, porém, lhes era de grande valor a sua identidade étnico-cultural.

Por duas vezes, uma em 1911 e outra durante o Estado Novo (1937-1945) o estado de Santa Catarina passou processos de unificação da língua a partir da nacionalização da língua, acarretando na proibição do uso da língua estrangeira (italiano e alemão) e, consequentemente, na tentativa de apagamento da identidade desses imigrantes e seus descendentes, pela imposição da língua portuguesa como "única língua legítima" (OLIVEIRA, 2009, p. 20).

Tais políticas linguísticas, seja referente ao período colonial com o objetivo de civilizar os índios, seja àquela implementada no governo Vargas a fim de tornar 'brasileiros' os imigrantes (e seus descendentes), propunham homogeneizar e reprimir tais línguas a partir da imposição de uma língua dominante e legítima, o português (OLIVEIRA, 2009; MAHER, 2013).

Neste sentido, concorda-se com a Declaração Universal dos Direitos Linguísticos, quando aborda, no Artigo 7, item 1, que "Todas as línguas são a expressão de uma identidade coletiva e de uma maneira distinta de apreender e descrever a realidade, pelo que devem poder beneficiar das condições necessárias ao seu desenvolvimento em todas as funções" (UNESCO, 1996, p. 6).

Tão logo, é preciso compreender e respeitar a diversidade linguística e cultural que constitui o Brasil a partir das diferentes comunidades de fala que aqui vivem ou escolheram viver. Os direitos linguísticos, conforme assinala a Declaração Universal dos Direitos Linguísticos (UNESCO, 1996) reforçam a luta e a resistência em favor da universalidade linguística e cultural, entendida nesse contexto a partir da concepção de diversidade, pluralidade linguística e cultural, em contraposição às tendências homogeneizadoras. A partir dessa contextualização inicial, se busca no presente texto, compreender as novas tentativas de "resgate" da língua alemã na região do Vale do Itajaí/SC a partir da implementação de escola uma bilíngue (português-alemão) e como se constitui o docente de língua estrangeira a partir dessa nova realidade.

O presente texto é constituído por introdução, seguida da seção que trata da língua portuguesa no processo de aculturação, mais adiante, na terceira seção, discute-se sobre os conceitos de germanidade e brasilidade. Na quarta seção, debruça-se sobre os documentos que fundamentam a implementação da escola bilíngue e, por fim, seguem as considerações finais e as referências. 


\section{A língua portuguesa no processo de aculturação}

No Brasil, as políticas de Estado que visavam a nacionalização da língua, se basearam em processos que impunham o uso do português como língua 'oficial' para os imigrantes e seus descendentes. Destaca-se que, historicamente, a língua é um dos principais elementos simbólicos na constituição do ideal de 'nação', bem como da delimitação de fronteira entre as diferentes nações (OLIVEIRA, 2009).

Nesse contexto, o Estado Novo, pontualmente entre os anos de 1937 e 1945, foi um período marcante para imigrantes que vieram da Europa, bem como aqueles que estavam instalados no país, mas que ainda faziam uso da sua língua de origem, pois a obrigatoriedade de uso da língua portuguesa, talvez tenha sido aquele de maior impacto educacional e cultural sentido. O uso obrigatório da língua portuguesa, imposto pelas políticas de Estado, impossibilitava os imigrantes (e/ou seus descendentes) de exercer a sua própria identidade, cultura e língua, como é o caso da língua alemã na região de Blumenau/SC. A vigilância sobre esses imigrantes era tamanha que "[...] quem possuísse qualquer objeto escrito - sobretudo em idioma alemão - era suspeito de traição ao Brasil, podendo até mesmo ser considerado simpatizante do nazismo" (SANTOS, 2009, p. 516).

Dessa maneira, as regiões de imigração passam a ser culturalmente influenciadas pelas políticas nacionalizadoras que o governo vinha implantando, políticas estas que determinavam a incorporação de referenciais linguísticos e culturais tidos como próprios de uma sociedade 'brasileira'. Nessa época, Gustavo Capanema, à frente do Ministério da Educação e Saúde, tomou diversas providências em relação à nacionalização das escolas étnicas, ou seja, das escolas localizadas em região de colonização estrangeira, visto que as instituições escolares eram consideradas fundamentais na formação do futuro cidadão. Desse modo, as práticas escolares deveriam conformar as futuras gerações para que estivessem de acordo com o ideário cívico 'nacional'.

Sobre isso, Kormann (1995, p. 136) relata que "a nacionalização se fazia presente em todos os setores da vida blumenauense, principalmente na área cultural e artística”, entretanto, o contexto educacional não pode ser desprezado, uma vez que a legislação tornou obrigatório o ensino em língua 'nacional', bem como a inclusão das disciplinas Linguagem, História e Geografia do Brasil, e a adoção de Cantos e Hinos Patrióticos, como forma de valorização e imposição do uso da língua portuguesa (LUNA, 2000). Destaca-se que, a implementação das políticas de nacionalização, imprimiu marcas profundas nas práticas, currículos e formação docente, nas escolas das regiões colonizadas por imigrantes em todo o estado catarinense. 
Considera-se importante destacar que em Santa Catarina, a Campanha de Nacionalização imposta por Getúlio Vargas não foi a primeira. A primeira tentativa de reformar o ensino no sentido de 'nacionalizar' os grupos étnicos das 'colônias ${ }^{4}$ alemãs', ocorreu ainda no ano de 1911, quando Nereu Ramos esteve à frente do governo do estado, e Orestes Guimarães foi contratado para ocupar o cargo de Inspetor Geral do Ensino, com a responsabilidade de realizar a 'reforma do ensino catarinense'.

Nessa época, conforme Fiori (1975), boa parte das escolas nas regiões 'coloniais' se caracterizavam como escolas 'estrangeiras', pois uma ou mais disciplinas eram ministradas em língua estrangeira, ainda que o professor fosse nascido no Brasil. Assim sendo, a partir de 1917 essas mesmas escolas deveriam estar sujeitas aos mesmos horários, programas e normas de ensino das escolas 'públicas' catarinenses, o que significaria que deveriam integrar o currículo as disciplinas de História do Brasil, Educação Cívica, Geográfica do Brasil, e todas estas deveriam ser ministradas em 'língua portuguesa', bem como cantos e hinos patrióticos brasileiros deveriam ser utilizados no cotidiano escolar. Nas escolas comunitárias ou particulares, entretanto, os professores continuavam sendo os mesmos, o que fazia com que, na ausência de fiscalização ou no intervalo entre as visitas dos inspetores nomeados por Orestes Guimarães, pouca coisa mudasse efetivamente. Além disso, a reforma proposta por Orestes Guimarães influenciava diretamente na prática educacional em aspectos determinados, mas não 'proibia' o uso do idioma alemão na escola e nem fora dela, e não atingiu diretamente as instituições culturais ou o cotidiano das famílias. Desse modo, pode-se dizer que a campanha de nacionalização iniciada em 1911 não se caracterizava como 'compulsória.

Conforme destaca Campos (2008), a nacionalização de algumas regiões e a integração do território e da população instalada em Santa Catarina era apontada como uma condição essencial para uma suposta "evolução econômica" e para o "progresso da sociedade". Assim sendo, para além das alterações no âmbito educacional, foram várias as medidas tomadas para que houvesse o controle estatal sobre as regiões ainda não assimiladas, ou seja, sobre os indivíduos e comunidades que por ventura estivessem em desacordo com os padrões de brasilidade que o Estado Novo pretendia fixar. Entre as medidas adotadas, consta instalação de um Batalhão do Exército em Blumenau. Sobre isso, Fáveri (2004, p. 69) afirma:

Por solicitação expressa de Nereu Ramos, em abril de 1939 foi instalado, em Blumenau, o $32^{\circ}$ Batalhão de Caçadores, com o objetivo de nacionalizar as regiões coloniais povoadas por imigrantes estrangeiros. [...] A estratégia

${ }^{4} \mathrm{O}$ termo colônia, nesse contexto, tem significado sociológico bem preciso: remete à organização comunitária dos imigrantes, num sentido de pertencimento étnico. Num primeiro momento as 'colônias urbanas' eram formadas, sobretudo, por gente oriunda dos projetos de colonização (SEYFERTH, 1999, p. 285). 
utilizada foi deslocar homens estranhos ou elementos heterogêneos ao meio, vindos do Norte e Nordeste do país, já que os homens do sul eram considerados pouco confiáveis politicamente para a visão militar da época.

Estes atos se fizeram necessários com o intuito de utilizar o Exército como apoio para a Campanha de Nacionalização e de coibir a difusão do discurso pangermanista do período divulgada por parte de alguns intelectuais blumenauenses. Conforme informações obtidas “[...] o Exército foi mobilizado para defender o país contra o 'inimigo interno' nas regiões onde viviam estrangeiros e seus descendentes no sul do país, tornando-se um dos principais agentes da Campanha de Nacionalização" (FROTSCHER, 2007, p. 119).

Para a implementação e a concretização do processo de nacionalização dos estrangeiros, além do uso do Exército como forma de coação para se forçar a adesão aos valores cívicos nacionais, este passou a servir de modelo para uma militarização das atividades escolares, com a implementação da realização de filas, de marcha, do uso do uniforme, da obediência ao horário, da valorização de ordem e da disciplina. Frotscher (2007, p. 128), sobre isso, afirma que "[...] além dos investimentos no ensino da língua portuguesa, da inibição do falar alemão e da militarização das crianças e jovens, incentivou- se também o culto à pátria, aos 'heróis' e aos símbolos nacionais". Nas escolas, portanto, buscou-se

[...] fazer das crianças e dos jovens os autênticos brasileiros necessários à nação em construção. Esse propósito foi também embasado por uma legislação educacional cujo conteúdo enfatizou as políticas de cunho nacionalizador. Nesse contexto, medidas emanadas do Ministério da Educação e Saúde foram carregadas com novas prescrições para a gestão e as práticas pedagógicas, tendo por objetivo transformar as instituições escolares em pólos cultivadores e irradiantes do ideário nacionalista. As escolas foram escolhidas como espaços vitais para a execução desse projeto por meio da criação de um modelo de infância e juventude que engendraria, no futuro, o trabalhador e patriota devotado (SANTOS, 2009, p. 512).

Além do controle do Estado sobre as crianças e jovens por intermédio dos processos educativos nacionalizadores, outras medidas, que atingiram mais diretamente a população adulta, foram tomadas. No ano de 1939, foi criado o Departamento de Imprensa e Propaganda - DIP, que passou a controlar as publicações, mais precisamente os jornais e revistas que antes circulavam livremente, impressos em língua alemã. Do mesmo modo, passou-se a exercer o controle sobre a radiodifusão. Conforme destaca Fáveri (2004), os hábitos e costumes da população passaram a ser alvo de observação, sendo proibido sintonizar rádios estrangeiras bem como a execução de músicas alemãs, pois, além de cultura, as letras das músicas divulgam também ideologias e propagandas tidas como indesejáveis. 
Outra instituição impactada pela proibição da língua alemã foi a Igreja Luterana, à qual pertencia grande parte da população de descendência germânica: "A partir de 1939 também a Igreja foi atingida em sua essência, quando novas leis eliminaram progressivamente, todas as línguas estrangeiras do culto da comunidade" (DREHER, 1984, p. 17). A igreja, em Blumenau, deveria, conforme Bethlem (1939, p. 188), ser alvo de tal campanha, pois, "a obrigatoriedade de sermões e prédicas apenas em nossa língua, e dos superiores de congregação e organizações religiosas serem brasileiros natos ou naturalizados, colaborará definitivamente para a solidificação do sistema”. Como consequência, a maior parte dos membros da comunidade luterana passou a não compreender o conteúdo da pregação, em língua portuguesa. Do mesmo modo, para que pudessem ser utilizados, os Hinos cantados nas prédicas, também precisaram ser traduzidos.

Para os luteranos essa 'tradução' era quase que inadmissível, visto que a conotação 'sagrada' da língua alemã para professar a fé luterana encontra raízes históricas, na tradução da Bíblia para a língua alemã por Martinho Lutero. A tradução da Bíblia objetivou a leitura da Bíblia pela população alemã, de modo que as "Escrituras Sagradas" pudessem fazer parte do cotidiano de todas as pessoas, sem distinção. Em sendo assim, a dissociação entre a religião protestante (luterana) tornou-se difícil. Sobre isso, Campos (2006, p. 268) afirma: “[...] A doutrina evangélica e a língua constituem o complexo étnico-religioso peculiar ao protestantismo alemão".

Embora os alemães e seus descendentes à época começaram a se considerar brasileiros, estes ainda procuravam manter vivo em seus lares o idioma alemão. Isso implica pensar que ora pudessem se considerar brasileiros e também germânicos, conforme se apresenta a próxima seção.

\section{Germanismo e Brasilidade}

De acordo com Seyferth (1994), a campanha nacionalizadora foi muito forte em torno do conceito de Deutschtum, mesmo nas áreas rurais o idioma alemão passou a ser menos falado, alternando-se com o português. Esta discussão em torno da manutenção do idioma alemão, mesmo tantos anos após a formação da 'colônia Blumenau', em 1850, pode estar relacionada ao constante fluxo imigratório da Alemanha para a região. Mesmo na década de 1920 ainda aconteciam estes deslocamentos, mesmo que em menor escala. Outro fator preocupante às políticas nacionalizadoras eram os chamados ‘novos alemães' (Neudeutscher). 
Neudeutscher não é um rótulo usado genericamente para designar imigrantes recém-chegados; no Vale do Itajaí, por exemplo, serviu para designar alemães que ingressaram no mercado de trabalho urbano como técnicos industriais, administradores, profissionais liberais, professores - portanto, numa posição de classe média ou alta [...] (SEYFERTH, 1994, p. 24).

Esse elemento 'germânico' estava presente nas pessoas e agregado a isto, a ideia de superioridade alemã em relação aos brasileiros, que permanecia evidente desde a chegada dos primeiros imigrantes, até a década de 1930. Organizados em torno do sentimento de germanidade (Deutschtum), a resistência dos imigrantes e seus descendentes dificultava integração ou aceitação da cultura brasileira como sendo 'suas'.

Conforme Campos (2006), entre os teuto-brasileiros, muitos utilizavam na fala (e leitura) o hochdeutsch (alemão gramatical), bem como dialetos alemães, enquanto outros utilizavam corruptelas da língua, pelo abrasileiramento de algumas expressões alemãs ou misturando palavras de língua alemã e portuguesa numa mesma frase. Embora advindos de regiões alemãs diversas, o nos permite tratar os imigrantes instalados em Blumenau como “alemães" é o uso da língua alemã. Segundo Braun (2010), a língua era o elo entre as diferentes regiões alemãs antes da unificação. Nesse contexto, ou seja, do uso do idioma alemão, os que emigraram eram "alemães", porque havia o idioma e a cultura que os uniam.

Pela própria questão de 'identificação', a língua alemã tornou o grupo teuto-brasileiro 'diferente' dos demais habitantes do território brasileiro (luso-brasileiros como modelo de 'identificação' da brasilidade). Tal fato também remonta à história, visto que a localização das colônias alemãs no Brasil esteve pautada em políticas de povoamento bastante específicas, que inicialmente, objetivavam povoar as terras devolutas, conforme destaca Seyferth (1999). Após a década de 1850, com a abolição do tráfico de africanos como escravos entre outros motivos, a imigração foi vista como possível solução para povoar os 'vazios demográficos'. Como resultado de tais políticas, esses grupos acabaram formando povoados com contornos razoavelmente definidos o que contribuiu para a conservação dos hábitos e costumes trazidos dos países de origem pelos imigrantes, além da língua, fatores que delinearam sua identidade étnica.

Assim sendo, até a década de 1930 o aculturamento desses imigrantes não foi uma exigência para sua permanência no país, esses se sentiram à vontade na manutenção de sua identidade étnica, bem como das instituições em torno das quais essa identidade era reforçada, tais como as associações culturais, de tiro, de canto coral, de teatro, bem como das igrejas e escolas. Destaca-se que além de mantidas pela própria comunidade, durante muito tempo essas instituições receberam subsídios financeiros vindos da Alemanha (EMMENDOERFER, 1950). 
O mesmo não pode ser dito em relação à ascensão de Getúlio Vargas à presidência e a instauração do Estado Novo, em meados da década de 1930, as línguas ditas 'estrangeiras' foram fortemente coibidas. Por isso, no período de 1937 a 1945, nas áreas de colonização estrangeiras da região Sul, houve grande movimentação, e, para que a "nacionalização de efetivasse', foi necessária quase que uma operação de guerra. Em Blumenau, se fez necessária a instalação de um Batalhão do Exército, por solicitação do governador do Estado de Santa Catarina. Esse Batalhão deveria servir de apoio na campanha infligida pelo governo federal. Em se tratando de Blumenau, mais precisamente, vários foram os setores da sociedade atingidos. Igrejas, escolas, sociedades culturais e de serviço, passaram por proibições, quando não foram impedidos de funcionar.

Dentre os motivos da solicitação do uso da força para implementar a cultura nacional, podemos citar a resistência dos descendentes em assimilar a cultura nacional em detrimento da 'sua' cultura (Deutschtum), o envolvimento da população em torno de instituições que colaboravam na manutenção de uma cultura e identidade étnica 'alemã', tais como a Igreja Luterana, associações culturais e os clubes de caça-e-tiro, a existência das chamadas 'escolas alemãs' (comunitárias ou particulares) bem como a presença de núcleos nazistas. A presença dos núcleos nazistas é registrada no livro O Punhal Nazista no Coração do Brasil, relacionando a estas sociedades nomes de pessoas como os do empresário Curt Hering e do maestro Heinz Geyer da Sociedade Teatral e Musical Frohsinn (atualmente Teatro Carlos Gomes) dentre outros (LARA RIBAS, 1944, p. 54-64). Frotscher (2007) nos dá exemplos de que as principais sociedades da região estavam vinculadas também a política e a elite local, como é o caso de Curt Hering, e de Peter Christian Feddersen.

Segundo Campos (2008), ante a evidência de fortalecer o projeto nacionalizador, nesse período foram também realizados, em Santa Catarina, os "Congressos de Brasilidade”, nos quais havia uma programação bastante extensa de conferências proferidas por autoridades e por intelectuais. O Congresso acontecia em vários municípios catarinenses, tais como Florianópolis, Joinville, Blumenau, entre outros, mas as falas eram também transmitidas pelas Rádios Difusoras, de modo a atingir a maior parcela da população, no sentido de impingir-lhes o sentido de "ser brasileiro".

A imposição do silenciamento linguístico provocou ressentimentos, marcou negativamente a trajetória de vida, como a experiência escolar, de vários falantes de línguas de imigração e precisa ser lembrada e problematizada como uma política de negação das diferenças e de reafirmação de um ideal monocultural (FRITZEN; NAZARO, 2018, p. 2). 
O campo cultural do município de Blumenau foi, portanto, o que sofreu maior intervenção do programa idealizado pelo Estado. A língua alemã, que era falada em casa, na escola e em diversos lugares, passou a ser fortemente coibida. Conforme menciona Seyferth (1981), na comunidade, o clima era de terror, pois muitas pessoas sequer poderiam falar em público, correndo o risco de prisão:

\begin{abstract}
Nessa tal de nacionalização queriam que todos falassem português da noite para o dia. Prenderam ate velhos que nada queriam com a política só porque falavam alemão em público. Mas antigamente o governo não proibiu falar alemão. Não providenciou escolas ou coisas semelhantes, que ensinasse as pessoas o portugues. Agora, depois de todos esses anos de indiferença, queriam que a gente falasse português sem sotaque (SEYFERTH, 1981, p. 188).
\end{abstract}

A comunidade que, desde o seu início como 'colônia', em 1889, esteve ligada às associações como: sociedades de canto (Gesangverein), sociedades de atiradores (Schützenverein), bandas musicais (Musikkapellen), de teatro, dentre outras formas associativistas da região. Todas essas tiveram suas atividades suspensas, paralisadas ou definitivamente interrompidas, em grande medida pelo uso do idioma alemão e pela manutenção de uma identidade que era 'teuto-brasileira', pois, conforme aponta Lara Ribas (1944, p. 53), as "sociedades teatrais, musicais e de cantores, as quais, por seus associados, nunca se preocuparam em difundir obras que não revelassem motivos estritamente alemães". Entretanto, todos esses elementos que antes faziam parte da cultura cotidiana das pessoas, de repente passaram a ser o motivo de acusação de subversão, justificando a perseguição cultural e linguística.

Além dos motivos já mencionados, outros mostram uma rede de sociabilidades em que políticos e empresários teuto-brasileiros que participavam e exerciam sua influência sobre os demais participantes. Sobre tal influência, Frotscher (2007, p. 40) aponta que:

Representantes de empresas de colonização alemã no Brasil mantinham contatos com o governo alemão e com entidades de apoio aos alemães no exterior, como o DAI (Deutsches Auslandsinstitut) e a VDA (Vereinfür das Deutschtum im Ausland, até 1933, e Volksbundfür das Deutschtum im Ausland, após esta data), entidade que tinha a tarefa de orientar culturalmente os cidadãos alemães e descendentes que viviam fora da Alemanha, apoiando principalmente escolas, bibliotecas, instituições culturais e associações.

Assim, se por um lado houvesse, talvez, alguns que quisessem trabalhar, antes da campanha, em prol de uma nacionalização, por outro lado, havia pressão, inclusive de meios externos, muito fortes, os quais não permitiam que a região de Blumenau desenvolvesse definitivamente este caráter nacionalizador. Ademais, a própria história do município 
contribuía para tal fato, pois, nos tempos da 'colônia', dada a falta de interesse dos órgãos oficiais em atender aos pedidos e necessidades dos colonos, bem como a ausência de um sistema educacional do Estado, fez com que os imigrantes procurassem alternativas próprias.

Além das instituições associativas culturais e recreativas, bem como hospitais e casas de apoio, as escolas particulares passaram a fazer parte do cotidiano dos blumenauenses, e assim permaneceram durante muitas décadas, como instituição de manutenção e valorização da cultura e da identidade étnica 'teuto-brasileira'.

Diante disto, a seção seguinte discorrerá sobre novas tentativas de 'resgate' da língua e da cultura alemã a partir da implementação da escola bilíngue na região do Vale do Itajaí/SC.

\section{Escola bilíngue e formação docente}

A partir da contextualização histórica sobre as políticas linguísticas implementadas no Brasil em torno de um projeto monolíngue e monocultural, inicialmente com a reforma pombaliana em 1757 e, mais adiante com a proibição das línguas trazidas pelos imigrantes (alemães, italianos, poloneses entre outros) em 1939, teve como propósito trazer a língua de status, de poder e de dominação sobre a língua de herança, minoritária a que as identificava pelo seu lugar de fala (FRITZEN, 2011).

É fato, conforme já se discorreu nas seções anteriores desse artigo, que tais línguas se perderam ao longo dessa história e as gerações que sucederam essa primeira geração de imigrantes que sentiram a proibição de sua língua, e consequentemente, a anulação de sua identidade, tiveram acesso apenas alguns dialetos falados em casa, à cultura germânica que conseguiu resistir ainda as ações da nacionalização (MAILER, 2003; FRITZEN, 2008; OLIVEIRA, 2009).

Algumas ações importantes permitiram aos poucos um resgate, talvez tímido da língua alemã em Blumenau, dentre elas: a inserção da língua alemã como língua estrangeira no currículo de duas escolas na rede municipal entre 1977 e 1978; na rede estadual de Santa Catarina, a partir do diálogo entre Universidade Federal de Santa Catarina e o governo do Estado de Santa Catarina, implementou-se o projeto "Reintrodução e Diversificação de Ofertas do Ensino de Línguas Estrangeiras no Primeiro e Segundo Graus da Rede Pública Estadual de Santa Catarina” entre 1984 e 1985, à época sete escolas pertencentes à rede pública municipal e estadual foram contempladas com o ensino do alemão como disciplina opcional no currículo; além disso, o curso de Letras da Universidade Regional de Blumenau, manteve a oferta do 
alemão/português entre os anos de 1968 e 1997 (MAILER, 2003; FRITZEN, 2008). Devido a falta de interesse e procura das pessoas por tal habilitação, o curso encerrou-se em 1997 (MAILER, 2003). Conforme ressalta a autora, houve a intenção de fazer a formação de professores para que pudessem atuar em comunidades que ainda trazem os resquícios/traços da língua alemã, portanto, um resgaste também da cultura local.

Em 2002 há uma retomada do projeto de "Escolas Bilíngues" pela atual gestão municipal (2001-2004), assim, como professores de alemão que atuavam na rede municipal de ensino de Blumenau, reuniram-se com o objetivo de resgatar a língua e a cultura alemã, assentados em uma política linguística direcionada a esse grupo minoritário de fala e assim, como a formação de professores de língua alemã. Para isso, contou-se com a consultoria do Instituto de Investigação e Desenvolvimento em Política Linguística - IPOL, tendo à época como coordenador o professor Dr. Gilvan Müller de Oliveira e contou-se com o apoio também da Secretaria Municipal de Educação de Blumenau. Nesse período deu-se início ao projeto piloto intitulado "Projeto de Política Lingüística para a Língua Alemã em Blumenau” conhecido também como projeto PLURES, sendo este tema e parte da pesquisa que compôs a dissertação de mestrado em Linguística na UFSC de autoria de Mailer (2003) (FRITZEN, 2008). Contudo, apesar de tais iniciativas em prol da manutenção da língua e cultura de um grupo cerceado, dentre outros, no período de Nacionalização no Brasil,

É preciso salientar, porém, que o fato de o projeto não ter nascido na própria (ou nas próprias) comunidade bilíngüe, como iniciativa do grupo étnicolingüístico, mas ter apenas sido apoiado pela comunidade, talvez tenha facilitado a tomada de decisão do novo governo. Normalmente a mudança de Prefeito e das autoridades educacionais cria na escola um clima de insegurança diante do poder do novo, do desconhecido. Embora os efeitos da formação em serviço das professoras já fossem visíveis, o projeto Escolas Bilíngües não chegou a se consolidar como uma bandeira de luta na comunidade escolar. Sendo assim, as políticas monolíngües adotadas até então, em conjunto com as memórias históricas de silenciamento pela repressão lingüística presentes na comunidade, deram o tom: a escola acatou as decisões da Secretaria de Educação sem questioná-las (FRITZEN, 2008, p. $35)$.

Ou seja, se por um lado, há iniciativa do governo municipal em respeito à preservação da língua e cultura desse grupo étnico, e consequentemente, o de compreensão dessa identidade alemã/brasileira constituída a partir do entrelaçamento de outras culturas locais (indígenas, espanhóis entre outros), por outro lado, é preciso atentar-se para o que de fato interessa a essa comunidade de fala, que precisa participar ativamente dessas decisões, portanto, deve ser ouvida sem sentir medo ou vergonha de sua língua materna (alemã) e de sua cultura. Do mesmo 
modo, a escola precisa ter autonomia para tais decisões a fim de garantir o direito linguístico (UNESCO, 1996) e o direito à aprendizagem dos sujeitos que ali se inscrevem (BRASIL, 1988; 1996).

Em 2005 com as mudanças de governo tal projeto foi interrompido pela atual gestão (2005-2013). Neste sentido, a língua alemã passou a não mais ser compreendida e ensinada na escola como a língua materna desses estudantes, mas sim, como língua estrangeira, bem como a formação continuada das professoras que atuavam com esse público-alvo também foi interrompida (FRITZEN, 2008). Entretanto, a despeito da inclusão do alemão como disciplina no currículo escolar, a língua portuguesa permaneceu sendo a única língua instrução formal/oficial. Assim, diversidade linguística continuava ameaçada no contexto escolar. Fritzen (2008, p. 28) assinala que "Isso pode levar, inclusive, as professoras que [falavam] alemão a se desobrigarem, a deixarem de usar o alemão em sala de aula, já que os alunos [tinham] aula específica da disciplina".

Em 2018 durante um ano inteiro de estudos realizados pela Secretaria Municipal de Educação de Blumenau o projeto "Escolas Bilíngues" é retomado. Para isso, foram realizadas visitas in loco em Unidades Escolares Particulares e de outros municípios que já tinham implantado diferentes propostas metodológicas para o Ensino Bilíngue, bem como questões legais de resolução de criação das escolas, grade curricular, materiais didáticos, formação inicial, assim como formação continuada dos profissionais que estariam vinculados aos processos de ensinar e aprender em alemão. Destaca-se que tais políticas estão em consonância com as Diretrizes Curriculares Nacionais para a Educação Básica, Resolução n. 4, de 13 de julho de 2010, (BRASIL, 2010), a partir da qual é reforçada a necessidade de se incluir no currículo pelo menos uma língua estrangeira moderna.

O documento sinaliza o reconhecimento da diversidade cultural no contexto onde as escolas estão inseridas e aponta para sua relação com o contexto global mais amplo, incluindo questões de trabalho e internacionalização, discussão bastante presente na esfera do ensino superior. Nesse caso, podemos inferir que as línguas de imigração, como línguas europeias, poderiam ter um papel importante nesse aspecto (FRIZTEN; NAZARO, 2018, p. 8).

A partir da vontade política da Prefeitura de Blumenau ${ }^{5}$ e em parceria com a Secretária Municipal de Educação de Blumenau - SEMED e, a partir desses estudos mapeou-se a escola que teria perfil para acolher o projeto piloto, haja vista a identidade da comunidade, assim como as vivências em língua alemã que permaneciam no lócus escolhido. A Unidade Escolar

${ }^{5}$ A partir da RESOLUÇÃO No01/2018/CME/BLUMENAU (BLUMENAU, 2018). 
escolhida localiza-se na zona rural do município de Blumenau e ainda desenvolve o projeto PLURES (iniciado em 2002) que possui um docente que ministra aulas de alemão e que trabalha este resgate e permanência da língua alemã duas vezes por semana com estudantes matriculados no pré-escolar e seguem até o nono ano do Ensino Fundamental.

Já identificado por Mailer (2003), hodiernamente, ainda se percebe que não há demanda suficiente de professores, tampouco pedagogas com formação linguística suficiente para o ensino bilíngue. Devido a essa fragilidade docente, a SEMED optou por trabalhar com uma pedagoga e uma professora de língua alemã juntas em sala de aula, atuando sobre e com o ensino da língua e da cultura alemã ${ }^{6}$. Deste modo, há uma preocupação e, portanto, que nega o bilinguismo subtrativo ${ }^{7}$ e defende-se que as línguas (alemão/português e seus dialetos) e letramentos (práticas sociais formais e informais) em ambas as línguas se desenvolvam juntas pelos estudantes. Em virtude disto, e com intuito de garantir o trabalho a partir da presença de duas docentes regentes em sala de aula, a Prefeitura Municipal de Blumenau publicou o Decreto $\mathrm{n}^{\mathrm{o}}$ 11.850, de 24 de julho de 2018 (BLUMENAU, 2018), garantindo esse trabalho conjunto.

Em primeira instância ocorreu uma formação aos docentes para compreender o que é o bilinguismo, assim como as diferentes abordagens bilíngues no contexto educacional e social. Referente à formação de docente, vem ocorrendo o diálogo com uma das Universidades do Vale do Itajaí para se reorganizar os cursos de licenciatura e Pedagogia para que se possa dar continuidade ao trabalho iniciado ${ }^{8}$. Vale ressaltar, que por enquanto, apenas a turma do primeiro ano está trabalhando nesse sistema e que gradativamente a escola piloto terá um trabalho bilíngue que finalize no nono ano.

Assim como, também os professores têm palestras e encontros semanais para discutir com os Coordenadores Curriculares da Secretaria Municipal de Educação de Blumenau e professores de universidades para estudar temas que perpassam o bilinguismo e a aprendizagem. A formação continuada ocorre semanalmente como premissa que é uma necessidade que se estude e reflita no/pelo/sobre o processo de aprendizagem de duas línguas (português-alemão).

Para os professores que possuem pouco conhecimento linguístico (referindo-se à língua alemã), assim como para qualificar a oralidade, escrita e leitura de funcionários da escola que

${ }^{6}$ Conforme Portfólio das Escolas Bilíngues: Línguas Alemã e Inglesa, no prelo.

${ }^{7}$ Ou seja, é aquele "em que as crianças substituem sua primeira língua, a língua de herança [neste caso, o alemão], pela língua majoritária oficial, por não encontrarem na escola nenhum suporte para sua língua" (FRITZEN, 2008, p. 34).

8 Conforme disponível em: https://www.blumenau.sc.gov.br/secretarias/secretaria-deeducacao/semed/professores-das-escolas-bilaingues-participam-de-formaacaao87. Acesso em: 13 jun. 2019. 
são da comunidade e já conhecem um pouco da língua, foi firmada parceria com um Instituto do município de Blumenau que vem ministrando aulas com esses profissionais para qualificar ainda mais os espaços de interação e interlocução em língua alemã favorecendo a comunidade de fala.

Além disso, viu-se a necessidade de ampliar a comunidade de fala em língua alemã que existia na Unidade Escolar, e não apenas se reportando aos docentes que atuam no local, mas de todos os seus partícipes. Então, se propôs colocar placas escolares bilíngues, bem como cartazes referentes ao cotidiano da língua alemã: calendário, avisos gerais aos estudantes, pais e funcionários, o cardápio das refeições dos recreios, jornais locais, e outros que seriam trabalhados com os estudantes posteriormente. A intenção é que a comunidade escolar (pais, professores entre outros) que circula pela escola possa interagir nos diversos espaços e com os diversos letramentos que permeiam nesse lócus.

Quanto aos processos de ensinar e aprender desenvolveu-se uma grade curricular diferenciada, visto que o objetivo é promover a língua em uso por meio da qualificação de uma comunidade que fala em alemão, sem se atentar para a alfabetização e o letramento em língua portuguesa. Para isso, no primeiro ano (iniciado em 2019), as aulas ocorrerão em um único período do dia com as aulas ministradas em ambas as línguas e, a partir do segundo ano (2020), com a ampliação de dez horas no contraturno. Esse contraturno ocorrerá apenas em língua alemã e será constituído por projetos interdisciplinares que envolvam tecnologias, ou seja, multiletramentos, arte e temas transversais como a conscientização da preservação do meio ambiente, hábitos culturais, entre outros assuntos que forem se delineando em conjunto com os conceitos estudados nas disciplinas.

Portanto, vê-se que as línguas minoritárias, como é o caso do alemão apresenta políticas linguísticas na região do Vale, em Blumenau, com vistas ao desenvolvimento da comunidade de fala e possível ampliação para demais comunidades. O objetivo da Prefeitura de Blumenau, por meio da Secretaria Municipal de Educação, é qualificar o uso da língua alemã para interação e comunicação, porém com zelo e cuidado na aprendizagem dos estudantes a fim de respeita a sua identidade linguística e cultural.

Outrossim, considera-se que apesar dos desafios ainda a serem superados nesse percurso, tal projeto busca resgatar a língua alemã (língua de herança) falada em casa, nos eventos sociais (festas, outros encontros sociais) (FRITZEN, 2008) que ocorrem naquela comunidade e, debruça-se também a garantir o direito a aprendizagem dessa língua a partir da leitura, da escrita, da oralidade, paralelamente caminhando ao lado do português. 


\section{Considerações finais}

O presente trabalho pautado em uma revisão de literatura buscou compreender as novas tentativas de "resgate" da língua alemã, bem como a manutenção étnico-cultural em Blumenau (SC) a partir da implementação de uma escola bilíngue (português-alemão).

Diante disto, compreende-se a partir desse artigo, a língua como direito (UNESCO, 1996), como identidade de um grupo de fala, neste caso, de imigrantes alemães advindos da Europa no século XVIII, bem como de seus descendentes. Diversidade linguística e cultural esta que constitui o povo brasileiro a partir dos diferentes grupos minoritários que aqui vivem ou escolheram viver.

Apesar do glotocídio (assassinato das línguas) (OLIVEIRA, 2009) a partir dos processos de unificação da língua alemã vinculados ao ideal de nacionalização no Brasil, ocorridos, o primeiro em 1911 (por Orestes Guimarães), e o segundo durante o Estado Novo (1937-1945), a língua alemã e a cultura teuto-brasileira mantêm-se presentes ainda nos dias hodiernos, como é o caso do município de Blumenau.

Considera-se, que se por um lado, a implementação da escola bilíngue apresenta uma política linguística inclusiva que busca valorizar a língua de um grupo minoritário ou de sua língua de herança, neste caso, o alemão, por outro lado, ainda há desafios a serem superados: a formação docente inicial e continuada bilíngue e o reconhecimento do dialeto alemão em uso por essa comunidade fala.

Ao passo que se lança um olhar mais atento para essas comunidades que ainda preservam a fala e cultura alemã, se questiona se a formação docente continuada para esses professores parte da sua realidade, das suas experiências, se problematiza o que já se perdeu e o que pode ser resgatado no tocante a língua e a cultura alemã e o que é vivido hoje naquela comunidade de fala. Ressalta-se que em momentos anteriores tais propostas de implementação das Escolas Bilíngues foram vistas pela comunidade de fala positivamente. Não houve avanço em detrimento de políticas posteriores não terem levado adiante esses projetos de relevância social, econômica e cultural.

Por fim, reforça-se que a presença da linguística nesse cenário (seja em 2002 e, mais recentemente em 2018 com a retomada das Escolas Bilíngues) é de suma importância, com vistas a criar políticas linguísticas e ferramentas que possam garantir a efetividade da Escola Bilíngue. Portanto, fazer o levantamento, a elaboração do projeto, a adequação de acordo com as políticas públicas vigentes, a elaboração do material didático, assim como a formação para os educadores e equipe pedagógica, bem como para os políticos que vão implementar essa 
política, uma vez, que a implementação de tais políticas linguísticas, acabam impactando diretamente na vida dessas pessoas.

Um dos desafios está em reconhecer e diagnosticar os conhecimentos referentes às línguas que os alunos trazem para a escola e, a partir desses conhecimentos, poder avançar e ampliar as possibilidades de inserção dos alunos em práticas de letramentos bi/plurilíngues valorizadas socialmente (ROSENBROCK; FRITZEN; HEINIG, 2018, p. 161).

Compreende-se assim, que as Escolas Bilíngues são um meio de permanência e êxito das duas culturas envolvidas (alemão-português) nesse processo de construção. Além disso, essas escolas passam a promover o resgate da identidade linguística e o linguista garante a continuidade do uso dessa língua por essa comunidade de fala, para que esse alemão falado em Blumenau, por exemplo, permaneça, perpetue para/em outras gerações.

\section{REFERÊNCIAS}

BETHLEM, Hugo. Vale do Itajaí: jornadas de civismo. Rio de Janeiro: J. Olympio, 1939.

BLUMENAU. Decreto no 11.850, de 24 de julho de 2018. Disponível em:

https://leismunicipais.com.br/a/sc/b/blumenau/decreto/2018/1185/11850/decreto-n-118502018-dispoe-sobre-a-criacao-no-sistema-municipal-de-ensino-de-blumenau-da-escolabilingue-nas-escolas-basicas-municipais-erich-klabunde-e-prof-fernando-ostermann. Acesso em: 11 jun. 2019.

BLUMENAU. Resolução No 01/2018/CME/BLUMENAU. Estabelece normas para a oferta da Escola Bilíngue em escolas de Educação Infantil e Ensino Fundamental pertencentes ao Sistema Municipal de Ensino de Blumenau. Blumenau: Conselho Municipal de Educação, 2018.

BLUMENAU. Professores das escolas bilíngues participam de formação. SEMED, 2018. Disponível em: https://www.blumenau.sc.gov.br/secretarias/secretaria-deeducacao/semed/professores-das-escolas-bilaingues-participam-de-formaacaao87. Acesso em: 13 jun. 2019.

BLUMENAU. Portfólio das Escolas Bilíngues: Línguas Alemãs e Inglesa. Blumenau: SEMED, no prelo.

BRASIL. Constituição da República Federativa do Brasil de 1988. [recurso eletrônico]. Brasília: Supremo Tribunal Federal, Secretaria de Documentação, 2018. Disponível em: http://www.stf.jus.br/arquivo/cms/legislacaoconstituicao/anexo/cf.pdf. Acesso em: 09 jun. 2019.

BRASIL. LEI No 9.394 de 20 de dezembro de 1996. Disponível em: http://portal.mec.gov.br/seesp/arquivos/pdf/lei9394_ldbn1.pdf. Acesso em: 09 jun. 2019. 
BRASIL. Diretrizes Curriculares Nacionais para a Educação Básica. Ministério da Educação. Conselho Nacional da Educação. Brasília: MEC, 2010.

BRAUN, Felipe Kuhn. História da imigração alemã no sul do Brasil. Porto Alegre: Costoli Soluções Gráficas, 2010.

CAMPOS, Cynthia Machado. A política da língua na era Vargas: proibição do falar alemão e resistências no Sul do Brasil. Campinas: Unicamp, 2006.

CAMPOS, Cynthia Machado. Santa Catarina, 1930: da degenerescência à regeneração. Florianópolis: Ed. da UFSC, 2008.

DREHER, Martin N. Igreja e germanidade. São Leopoldo: Sinodal, 1984.

EMMENDOERFER, Frei Ernesto. O ensino particular em Blumenau. p. 283-297. In:

CENTENÁRIO DE BLUMENAU. Blumenau: Edição da Comissão de Festejos, 1950.

FÁVERI, Marlene de. Memórias de uma (outra) guerra: cotidiano e medo durante a Segunda Guerra em Santa Catarina. Florianópolis: Ed. da UFSC; Itajaí: Ed. da Univali, 2004.

FIORI, Neide Almeida. Aspectos da evolução do ensino público: ensino público e políticas de assimilação cultural no estado de Santa Catarina nos períodos imperial e republicano. Florianópolis: Secretaria da Educação, 1975.

FRITZEN, Maristela Pereira. "Ich kann mein Name mit letra junta und letra solta schreiben": bilingüismo e letramento em uma escola rural localizada em zona de imigração alemã no Sul do Brasil. Tese (doutorado) - Universidade Estadual de Campinas, Instituto de Estudos da Linguagem. Campinas, SP: [s.n.], 2008. Disponível em: https://edisciplinas.usp.br/pluginfile.php/3524047/mod_resource/content/3/tese\%20Pereira\%2 0Fritzen\%202007.pdf. Acesso em: 09 jun. 2019.

FRITZEN, Maristela Pereira. Reflexões sobre práticas de letramento em contexto escolar de língua minoritária. DELTA [online], vol. 27, n. 1, p. 63-76, 2011. Disponível em: http://www.scielo.br/scielo.php?script=sci_abstract\&pid=S0102$44502011000100004 \& \operatorname{lng}=\mathrm{e} \& \operatorname{lng}=$ pt. Acesso em: 09 jun. 2019.

FRITZEN, Maristela Pereira; NAZARO, Ana Carolina de Souza. Línguas adicionais em escolas públicas: discussão a partir de um cenário intercultural. Educação em Revista. n. 34, p. 1-27, 2018. Disponível em: http://www.scielo.br/pdf/edur/v34/1982-6621-edur-34e162012.pd. Acesso em: 09 jun. 2019.

FROTSCHER, Méri. Identidades móveis: práticas e discursos das elites de Blumenau. Blumenau: Edifurb, 2007.

KORMANN, Edith. Blumenau: arte, cultura e as histórias de sua gente (1850-1995). v. 3. Blumenau: Edith Kormann, 1995.

LARA RIBAS, Antonio de. O punhal nazista no coração do Brasil. 2. ed. Florianópolis Imprensa Oficial, 1944. 
LUNA, José Marcelo Freitas de. O português na Escola Alemã de Blumenau: da formação à extinção de uma prática - Ensinávamos e aprendíamos a língua do Brasil. Itajaí: Univali; Blumenau: Furb, 2000.

MAHER, Terezinha Machado. Ecos e resistência: políticas linguísticas e línguas minoritárias no Brasil. In: NICOLAIDES, Christine; SILVA, Kleber Aparecido da; TILIO, Rogério; ROCHA, Claudia Hilsdorf. (Orgs.). Política e políticas linguísticas. Campinas, SP: Pontes Editores, 2013.

MAILER, Valéria Contrucci de Oliveira. O alemão em Blumenau: uma questão de identidade e cidadania. 2003. 96 p. Dissertação (mestrado) - Programa de Pós-Graduação em Linguística, Centro de Comunicação e Expressão, Universidade Federal de Santa Catarina, Florianópolis, 2003. Disponível em:

https://repositorio.ufsc.br/xmlui/bitstream/handle/123456789/85489/192379.pdf?sequence=1 \&isAllowed=y. Acessado em: 10 abr. 2019.

OLIVEIRA, Gilvan Müller de. Plurilinguismo no Brasil: repressão e resistência linguística. Synergies Brésil nº 7, 2009, pp. 19-26. Disponível em:

https://gerflint.fr/Base/Bresil7/gilvan.pdf. Acesso em: 12 mai. 2019.

ROSENBROCK, Emilia; FRITZEN, Maristela Pereira; HEINIG, Otília Lizete de Oliveira Martins. (Inter)relações entre práticas de letramentos na escrita de narrativas em alemão e em português por crianças que vivem em contexto de alemão como língua de herança familiar. Pandaemonium Germanicum, São Paulo, v. 21, n. 33, p. 136-164, abr. 2018. Disponível em: http://www.scielo.br/scielo.php?script=sci_arttext\&pid=S1982-

88372018000100136\&lng=en\&nrm=iso. Acesso em: 11 jun. 2019.

SANTOS, Ademir Valdir dos. A política educacional nacionalista e o aspecto linguístico: vestígios na escola primária. Revista Brasileira de Estudos Pedagógicos (RBEP), Brasília, v. 90, n. 225, p. 511-527, maio/ago. 2009. Disponível em:

http://www.rbep.inep.gov.br/index.php/rbep/article/view/522/505. Acesso em: 23 abr. 2017.

SEYFERTH, Giralda. Nacionalismo e identidade étnica: a ideologia e o grupo étnico teutobrasileito numa comunidade do Vale do Itajaí. Florianópolis: Fundação Catarinense de Cultura, 1981.

SEYFERTH, Giralda. A identidade teuto-brasileira numa perspectiva histórica. p. 11-28. In: MAUCH, Cláudia; VASCONCELLOS, Naira. Os alemães no sul do Brasil: cultura, etnicidade, história. Canoas: Editora da ULBRA, 1994.

SEYFERTH, Giralda. A colonização alemã no Brasil: etnicidade e conflito. In.: FAUSTO, Boris (org.). Fazer a América: a imigração em massa para a América Latina. 2. ed. São Paulo: EDUSP, p. 273-314, 1999.

UNESCO. Declaração Universal dos Direitos Linguísticos. 1996. Disponível em: http://www.dhnet.org.br/direitos/deconu/a_pdf/dec_universal_direitos_linguisticos.pdf. Acesso em: 13 mai. 2019. 


\section{Como referenciar este artigo}

PROBST, Melissa.; FISTAROL, Caique Fernando da Silva.; POTTMEIER, Sandra. Da nacionalização à escola bilíngue: reflexões sobre a educação linguística em Blumenau/SC. Rev. EntreLínguas, Araraquara, v. 5, n. 1, p. 142-161, jan./jun. 2019. E-ISSN: 2447-3529. DOI: 10.29051/el.v5i1.12791

Submetido em: 26/03/2018

Aprovado em: 12/04/2019

Publicado em: 30/04/2019 